\title{
Dos Conceitos de Certeza e a Lógica e PRobabilidade - A Crítica AO ESTADO HOBBESIANO E O ENSEJO PARA A POSSIBILIDADE DE UMA FILOSOFIA POLÍTICA EM LEIBNIZ
}

\section{[ON CERTAIN AND LOGIC AND PROBABILITY - CRITICISM TO THE HOBBESIAN STATE AND THE POSSIBILITY OF A POLITICAL PHILOSOPHY IN LEIBNIZ]}

\author{
Cristiano Bonneau * \\ Universidade Federal da Paraíba, Brasil
}

\begin{abstract}
Resumo: Este texto parte de algumas considerações de Leibniz sobre a filosofia de Hobbes, em especial, sobre a questão da liberdade. Leibniz discute o problema da liberdade em face à física hobbesiana e seu potencial determinista. As idéias hobbesianas sobre a natureza humana e a razão têm valor inestimável para a consolidação de uma tradição de teóricos da política. Tendo como ponto de partida este contexto, analisamos as possibilidades de pensar sobre uma filosofia política na filosofia de Leibniz.
\end{abstract}

Palavras-Chave: Hobbes; Leibniz; Liberdade; Razão e Política
ABSTRACT: This paper begins with some considerations on Leibniz's philosophy of Hobbes, in particular on the issue of freedom. Leibniz discusses the problem of freedom in the face of physical Hobbesian and its potential deterministic. The Hobbesian ideas about human nature and reason are invaluable to the consolidation of a tradition of political theorists. Taking as a starting point this context, we analyze the possibilities of thinking about political philosophy in the philosophy of Leibniz.

KEYwORDS: Hobbes; Leibniz; Freedom; Reason and Politics

\section{INTRODUÇÃO}

Universo de Leibniz é vasto e merece ser considerado nesta direção. Filosofia, entre outras disciplinas... tudo em um homem só, como uma enciclopédia. Esta universalidade do saber era algo comum entre os modernos, bastando recorrer a Descartes, Fichte, Kant ou Hegel. Em grande medida, as características que compõem a identidade do filósofo se dão por este caráter holístico e exponencialmente extensivo do conhecimento. Porém, esta fama de ser abrangente e universal tem outro lado obscuro para Leibniz: comparando-o com outros autores importantes, ele parece ser vítima de um escasso volume de leitura. Sua fama como em um slogan, é proporcional ao desconhecimento de seus escritos. Por essas razões, o pensamento leibniziano pode-nos suscitar questões importantes, as quais ainda passam longe de uma solução adequada. A sua capacidade de tratar dos mais diversos temas e ainda, o número grandioso de

* Professor de Filosofia no Depto. de Ciências Sociais do Centro-CCAE-UFPB. Doutor em Filosofia pelo Programa de Pós-Graduação de Filosofia da Universidade de São Paulo-USP com periodo sanduiche em Université Paris 1 Pantheon-Sorbonne (Orientador: Chantal Jaquet). m@ilto: crbonneau1@gmail.com 
correspondentes, o transformaram me uma das figuras filosóficas mais ativas de seu tempo.

O hermetismo de pequenos escritos, como a Monadologia ou A origem Radical das Coisas, se contrastam com obras cuja exposição recorre a várias sentenças e proposições, exaustivamente explicadas e explicitadas, vide a Teodicéia, Os Novos Ensaios sobre o Entendimento Humano ou ainda, o Sistema Religioso de Leibniz ${ }^{1}$. Seu sumiço do cenário da filosofia, após gozar de enorme sucesso pela via do trabalho de Christian Wolff na academia alemã, tem em dois outros filósofos as suas razões. $\mathrm{O}$ primeiro é o aparecimento da crítica kantiana, juntamente com a depreciação da metafísica leibniziana e o segundo está na força do espinosismo, que só na Alemanha do século XVIII virou um jargão do qual bastava a si mesmo para ofender seu oponente, ao chamá-lo de espinosista.

No oceano da filosofia leibniziana (e essa imagem que gostaríamos de explorar), encontramos os destroços de um grande navio naufragado, que ficam a flutuar neste mar sem fim para a nossa capacidade de navegação. Por vez ou outra, encontramos a boiar grandes destroços e ao analisarmos de forma mais concentrada, percebemos a dificuldade de compreender de que material eles são feitos e também, a riqueza de mistérios que se encontram em cada uma destas peças à deriva.

A solidez e capacidade de flutuação de cada uma destas partes são bem superiores à própria embarcação em que nos encontramos, daí sermos tentados a trocar o que consideramos o nosso navio inteiro, por fragmentos de uma potente nau, que contemplamos mesmo na superfície a sua totalidade, da qual de fato temos acesso apenas a uma de suas pequenas partes. Neste contexto, desejamos colocar em questão um destes fragmentos do pensamento de Leibniz e podem vir a ser causa de uma polêmica: existe uma filosofia política em seu colosso filosófico? De repente, outra enorme nau se aproxima e encobre o sol em uma grande área do alto mar. Sua sombra nos permite perceber sua magnitude.

A filosofia de Hobbes gozou sempre de uma fama multiforme ${ }^{2}$. De um adjetivo maldito, ao ser taxado de hobbesiano até um dos mais importantes e fecundos pensadores da política. Para tal, partiremos das considerações de Leibniz, e sua leitura sobre a filosofia de Hobbes. Dentre a celebridade de ambos e as várias desavenças, existe um ponto de partida para os dois: a física-matemática. Enquanto concordam neste ponto, Leibniz critica ferrenhamente a redução que Hobbes faz da questão da vontade, a desintegração das partículas em nome da unidade do soberano e principalmente, o processo de definhamento e extinção da liberdade dos indivíduos. Portanto, três temas polêmicos na filosofia: a vontade, a identidade e a liberdade, que para Leibniz se fazem fundamentais em sua exposição sobre o homem, cujo desfecho coloca o pensador alemão em colisão com a proposta política desenvolvida por Hobbes. Leibniz ao se referir a Hobbes escreve que:

"Faz notar muito bem que não há nada que se faça ao acaso, ou melhor, que o acaso não significa senão a ignorância das causas que produzem o efeito, e que para cada efeito é preciso um concurso (concours) de todas as condições suficientes, anteriores ao evento." 3

Se o principio da racionalidade aproxima estes dois pensadores, ao mesmo tempo, adentrando em suas filosofias, dois sistemas insurgem por vezes concordantes, e 
outras, brutalmente antepostos. Não nos propomos aqui a promover o choque de dois titãs e esperar à sombra para ver o que sobra desta titanomaquia. Ao explorar as diferenças entre os dois filósofos em questão, neste texto, na discussão que gira em torno da liberdade, estão em jogo questões tão difíceis quanto estas, desde o problema da Teodicéia até o da legitimidade do poder. O mesmo principio de razão, que para Hobbes fundamenta e explica a necessidade do mundo, demonstrando que a existência é simples, desde que entendida racionalmente, por sua vez, torna-se assumido por Leibniz como o principio de razão suficiente. Mais do que apontar para os efeitos e suas causas, é desenvolver uma idéia de que a redução racional de uma determinada causa, não encerra para o homem a fecundidade de caminhos pelos quais os fenômenos podem assumir suas mais variadas formas. Esta análise propõem a diferença entre as duas filosofias em questão: a lógica de certeza e a lógica do possível. A distinção entre ambas, apontam para formas distintas de sistematizar a realidade.

\section{RAZÃo e IMAGINAÇ̃̃o}

A idéia de imaginação em Hobbes é profundamente explorada por seus leitores. No momento em que os homens firmam um pacto com o objetivo de viverem em sociedade, a imaginação, que forjara um cenário de competição e concorrência entre todos, torna-se o combustível essencial para que a política e a sociedade sejam assumidas. É para evitá-la em seus possíveis danos, que a razão se torna a mediadora de todos os componentes do Estado. Esta questão é crucial a tal ponto de desencadearem pontos de inflexão fundamentais nas filosofias de Descartes e Espinosa. A idéia hobbesiana de imaginação se desenvolve em contraposição à sua noção de pensamento e razão. Distinguir estes dois momentos da filosofia de Hobbes é traçar as diferenças entre uma condição e outra no espírito do homem, e principalmente esclarecer a concepção de razão e quais são seus desdobramentos, neste influxo que parte do interior de cada homem e se estabelece em uma idéia de estado.

E ainda, enquanto uma teoria, o conhecimento em Hobbes se afirma ao tratar das diversas formas pelas quais a imaginação se estabelece, seja no momento da passagem de uma paixão para outra, ou ao procurarmos definir algumas idéias importantes como a de liberdade, por exemplo. No Leviatã, Hobbes recorre ao tema da imaginação em vários momentos. Na ocasião, o oitavo capítulo do primeiro livro se torna um exemplo. Neste, a questão é demonstrar o que é a virtude, em especial a virtude intelectual. Não obstante, esta pode ser atribuída como uma potência da mente, que é dividida em cognitiva (que também podem ser imaginativa ou conceptiva) e motriz ${ }^{4}$. Fiquemos apenas com a primeira potência, na qual a idéia de virtude aparece.

Ao relacionar a virtude ao talento, Hobbes promove uma divisão: as virtudes são, ou naturais ou adquiridas. Nenhuma ou outra são consideradas inatas ao homem, mas o seu uso é considerado como um talento natural. Ele prossegue na análise afirmando que o talento natural consiste em celeridade da imaginação ${ }^{5}$ e na firmeza da direção. Direção insistente e boa velocidade aparecem como contrários à imbecibilidade, estupidez e imaginação lenta. Isto é para Hobbes a forma como se dá a sucessão de pensamentos, e sua diferença de rapidez não é apenas o que se impõem enquanto as diferentes paixões pelas quais os homens agem, mas o que afirma como 
singular entre um homem e outro. Estas diferenças são aquelas que podemos julgar e avaliar, promovendo distanciamentos e semelhanças, tendo em vista estabelecer "para que servem ou se servem para tal fim." Daí segue que, para Hobbes a capacidade de perceber somente o que é semelhante tem como causa a imaginação.

Neste caso, não há juízo e nem virtude. Os sujeitos de boa imaginação perdem de vista a avaliação dos objetos. Por outro lado, distinguir, discernir e julgar além do que avaliamos como iguais e também aquilo que distingue uma coisa da outra, é considerado pelo filósofo um bom juízo. Vejamos que aquilo pelo qual se considera bom juízo ou a capacidade de racionalizar os fenômenos, sejam eles objetos isolados ou fatos, é sumariamente destituído de qualquer capacidade ou forma de imaginação. $\mathrm{O}$ raciocínio aqui prevê a construção de um discurso, mas demonstra que a razão é a chave para a constituição do pensamento, que indutivamente nos conduz entre as suas partes e aritmeticamente dimensiona a sua totalidade, de forma segura, sem saltos e se feito corretamente, sem erros. $\mathrm{O}$ objetivo deste processo de inferência que corresponde ao uso e finalidade do próprio pensamento revela que para Hobbes esta seria o método mais adequado de empregarmos nosso raciocínio, senão usando a imaginação como velas auxiliares na direção do vento correto, pelo menos a extinguindo de todo o trabalho do pensamento, para que a mesma não atrapalhe a embarcação em sua rota certeira.

Uma das noções fundamentais que embasam esta distinção entre imaginação e razão é derivada da física. Se a velocidade é o meio pelo qual pode ser medida a eficácia ou não de um determinado pensamento, ser veloz ou mais veloz ainda depende da passagem de movimento de um objeto para outro. Deste modo Hobbes expõem que todo efeito produzido ou que virá a ser produzido algum dia tem uma causa necessária. ${ }^{7}$ Portanto não há outra forma de compreender este movimento da razão, que deveria promover sempre as semelhanças e diferenças entre os objetos, senão pelas noções físicas que Hobbes emprega. A velocidade é o acidente pelo qual a substância aparece. Portanto, a sua desenvoltura, neste caso, rapidez e segurança, corresponde sempre ao aumento ou diminuição da capacidade racional do homem.

A imaginação aqui, ou conduz o pensamento à uma velocidade incompatível com ele mesmo, ou termina em um lugar errado. As regras da razão em Hobbes, que por sua vez são responsáveis pelo raciocínio e pela linguagem, são a demonstração de que a razão é pensada como movimento, em primeiro lugar e necessária ao homem e ao estado em segundo lugar. "Sua filosofia, que afirma que só os corpos são substâncias", proposição de Leibniz que demonstra que o que existe para Hobbes são substâncias e é delas que se deve inferir a existência das coisas. A substância enquanto corpo está sujeita somente às leis da física - é nesta que devemos buscar o pensamento de Hobbes. O seu materialismo, do qual a mudança é a adição ou subtração das partes, refletindo em acidentes, de acordo com certa velocidade e movimento, aponta que a mesma razão que rege os fenômenos, deveria ser a mesma pela qual estaríamos aptos a utilizar para pensá-los e finalmente, interferir nestes.

Uma questão fundamental nos remete ao fato de que a imaginação pode conduzir o homem para a ignorância das causas dos fatos e fenômenos. O distanciamento dos motivos e razões que culminaram neste ou naquele evento ou fenômeno faz com que o homem se utilize cada vez mais de recursos exteriores a ele mesmo e recorra cada vez menos a si para compreender e resolver um determinado 
caso. A distinção que Hobbes desenvolve entre costumes e razão é uma das luzes importantes na demonstração do papel do exercício do raciocínio em todas as instâncias de decisões sobre a vida. ${ }^{9}$ Após definir costume como "aquelas qualidades humanas que dizem respeito a uma vida em comum pacífica e harmoniosa"10, Hobbes propõem uma definição aritmética de felicidade. Esta é:

“(...)um contínuo progresso do desejo, de um objeto para outro, não sendo a obtenção do primeiro outra coisa senão o caminho para conseguir o segundo. Sendo a causa disto que o objeto do desejo do homem não é gozar apenas uma vez, e só por uma momento, mas garantir para sempre os caminhos de seu desejo futuro."11

Considerando que a "felicidade desta vida não consiste no repouso de um espírito satisfeito"12, esta inquietude natural do homem é preenchida por uma tendência geral, que lança a condição humana a um "perpétuo e irrequieto desejo de poder e mais poder, que cessa apenas com a morte." 13 Tendo em vista "que por natureza todos os homens são iguais"14, o movimento, condição ontológica de todas as substancias, inclusive do homem, é a tendência natural de todo o ser. A natureza para Hobbes é dinâmica, marcada pelo choque e entrechoque de todas as coisas que existem, que se aglutinam e se separam, formando este ou aquele corpo e enquanto tal, mantendo-se existente.

Hobbes desenvolve seu pensamento em torno da idéia de ratio naturalis, procurando demonstrar que esta “(...)é inata em todo homem; pois qualquer um raciocina até certo ponto a acerca de algumas coisas." ${ }^{15}$ Esta crença ou pressuposto de uma natureza humana que se baseia na racionalidade, corresponde a herança do legado galileano que esquadrinha o universo a partir de um movimento seguro e uniforme, sempre submetido ao cálculo e à geometria. Por esta via, Hobbes desenvolve o seu pensamento que se transmuta da física para a política, na exigência de procurar luzes sobre a influência da igreja nas questões políticas do estado. Procura a origem pela qual os homens agem em suas vidas, culminando na sua presença entre a comunidade civil, ou seja, na política. A sua proposta de desenvolver uma linha demonstrativa- que passa pelo corpo, ou natureza dos corpos; pela vontade, ou pelo homem individual; e finalmente, pela reunião destes homens, ou política- intenta traçar uma tese realista ${ }^{16}$. Se a verità effettuale se afirma na própria ação humana, buscando nesta a realidade efetiva dos fatos, Hobbes submete esta análise a uma minúcia ainda maior, quando pretende explicar os fenômenos partindo da física. A questão nos aparece na medida em que os fenômenos da vida em sociedade carecem de uma origem na qual, o fato social constitui-se o resultado de um momento anterior, cuja gênese esta em uma natureza humana que por sua vez, precisa ser demonstrada. Hobbes separa enquanto objeto de sua ciência aqueles que correspondem a própria natureza daqueles que seriam relativos a vida civil. Não entraremos, por ora, nesta distinção fundamental, pois o que pretendemos é delinear alguns elementos que permitam visualizar a idéia hobbesiana de razão.

\section{LEIBNIZ E HobBES}

Hobbes é claro quanto à sua compreensão de razão, apontando que "por 
raciocínio, entendo cálculo. (...) tido raciocínio se reduz às duas operações da mente: adição e subtração." ${ }^{\prime 17}$ Esta concepção fundamental para o pensamento de Hobbes tem consequências importantes para a sua filosofia política. Mesmo admitindo as paixões e suas forças, a racionalidade é (ou deveria ser) o guia operante mais importante no tocante às decisões políticas. O Leviatã nos apresenta uma extensa exposição de sentimentos e paixões importantes na vida dos homens, e que são causa, ora de seu sucesso, ora de sua ruína. Hobbes nos apresenta uma espécie de mapa da psicologia humana ${ }^{18}$, tratando de uma enormidade de tipos e espécies de afetos, procurando determinar uma lógica pela qual um sentimento surge em detrimento de outro e quais as consequências deste aparecimento. Este conhecimento revela uma ciência da moral em Hobbes, derivada em último grau de uma concepção racional de homem. Nesta perspectiva, Hobbes alega que "(...)as guerras civis e, com elas, as maiores calamidades são conseqüências da ignorância dos deveres, isto é, da ciência moral, atribuímos com razão ao conhecimento destes as vantagens contrárias." ${ }^{19} \mathrm{Na}$ razão está depositada a saída para o estado de barbárie e de sua capacidade é que devem surgir os valores para qualquer vida em comunidade. Do contrário, as paixões, representando forças da própria natureza humana seriam incapazes de manter um vínculo que assegurasse a segurança de quem quer que seja.

"Portanto, a verdadeira razão é uma lei certa, que (já que faz parte da natureza
humana, tanto quanto qualquer outra faculdade ou afecção da mente) também é
denominada natural. Por conseguinte, assim defino a lei da natureza: é o ditame
da reta razão no tocante àquelas coisas que, na medida de nossas capacidades,
devemos fazer, ou omitir, a fim de assegurar a conservação da vida e das
partes de nosso corpo."20

Parece ser possível admitir que Leibniz e Hobbes sejam convergentes em alguns pontos quanto à importância da razão em seus sistemas filosóficos. Porém, no tocante ao conceito de razão utilizado por um e por outro, acaba-se por marcar fronteiras intransponíveis, cujas consequências revelam formas de conceber a sociedade, radicalmente diferentes. Leibniz procura percorrer o itinerário proposto por Hobbes tendo como objetivo compreendê-lo e ainda, procurar de que forma se estabelece no interior do pensamento do filósofo inglês o seu encadeamento de verdades. Se a razão conduz os dois pensadores em teses que os aproximam, a idéia de necessidade acaba por distanciá-los e torna-os opositores. Este ponto é decisivo, pois reside aí a noção de liberdade.

Conciliar as esferas que determinam o que é livre e o que é necessário constitui em um dos problemas que incitam mais polêmicas e discussões dentre os pensadores do século XVII. Após elogiar o caráter demonstrativo da concepção de liberdade em Hobbes, considerando que sua noção de livre, quanto ao aspecto formal é bem constituída, Leibniz comenta que desde que, "seja considerada em um sentido geral comum às substâncias inteligentes e não- inteligentes, ao dizer que uma coisa é considerada como livre quando a potência (puissance) que ela tem não é impedida por uma coisa externa." 21 Em concordância quanto à sua definição, Leibniz apresenta os problemas relativos à uma concepção de razão vinculada com o que seja livre e necessário, em especial, quando a questão fica circunscrita somente à idéia de necessidade.

Leibniz reconhece o mérito da filosofia de Hobbes em buscar um princípio que 
venha explicar as causas dos fenômenos, inclusive da própria ação política. A razão torna-se um vínculo necessário entre os acontecimentos e suas motivações, colocandose contra as superstições e as crendices que ao apontar para a causalidade dos fenômenos, acabam por sustentar uma miríade de argumentação insólita e desproporcional em relação às causas e como estas se manifestam. Um pensamento para Leibniz é o encadeamento de idéias; a verdade torna-se o encadeamento adequado destas idéias. A racionalidade torna-se o meio pelo qual o mundo é vislumbrado. Hobbes reduz, por exemplo, as paixões da alma aos corpos e seus movimentos, o que conduz todo o processo à física e como uma aritmética pode ser calculado e medido de acordo com sua manifestação. No entanto, esta redução é para Leibniz a introdução de uma determinação que tem por consequência a exclusão da liberdade.

Enquanto ser livre para Hobbes é não ser impedido por outro na medida em que haja algo que se mova em velocidade constante e uniforme sem nenhum obstáculo, para Leibniz a liberdade vincula-se à escolha. A política neste caso torna-se mais do que um jogo de forças, predeterminado por corpos que agem conforme suas condições passionais, dirigindo-se em seu caminho até encontrar uma força contrária - a atividade política esta no campo das alternativas, em escolher entre uma ou outra possibilidade. As ações do homem, dentre as quais poderíamos incluir a atividade da política encontram-se no campo das contingências. O problema que reflete a relação entre o contingente e o necessário também é polêmico e complexo. A questão, a saber, se toda contingência é necessária. Se a resposta for afirmativa, não há distinção entre uma e outra e tudo se torna necessário, ou até mesmo, contingente. Leibniz compreende o problema em dois momentos distintos, porém, interligados.

O necessário é toda e qualquer possibilidade da existência, seja física ou metafísica. Porém, para Leibniz a necessidade não se dá na esfera da moralidade. Esta, por vezes, confirma algo que seja necessário, mas é sempre contingente, pois depende de uma ou mais escolhas. Desta forma, é possível afirmar a bondade e a liberdade de Deus, que não agiu necessariamente, por exemplo, ao criar o homem. Deus agiu livremente ao forjar o homem, caso contrário, seria inviável admitir que a humanidade também tivesse liberdade e poder de escolha. A liberdade consiste em:

“(...)inteligência, que envolve um conhecimento distinto do objeto da deliberação; na espontaneidade, a partir da qual nós nos determinamos; e na contingência, isto é, na exclusão da necessidade lógica ou metafísica. A inteligência é como que a alma da liberdade, e o resto é como que o seu corpo e a sua base." 22

Inteligência, espontaneidade e contingência são as condições necessárias para que haja a deliberação. Escolher de forma livre pressupõe que haja poder e conhecimento que possa fazê-lo, independente se a ação é considerada boa ou má. A racionalidade para Leibniz, operando também como o princípio pelo qual a razão se torna suficiente para vislumbrar todas as determinações, tem concordância com Hobbes até este ponto. Ultrapassa-o quando amplia o horizonte compreensivo da idéia de razão, ao incorporar nesta a noção de possibilidade. É no campo do possível que uma ação pode ter sua ocorrência ou não. $\mathrm{O}$ dilema do asno de Buridan é clássico. $\mathrm{O}$ animal, entre dois maços de feno rigorosamente iguais morre de fome, pois, agindo pela necessidade não consegue decidir se comerá o monte da direita ou da esquerda.

Para Leibniz, mediante uma situação previamente dada, não é só possível 
deliberar entre um e outro maço de feno, mas também, não dirigir-se à nenhum. As condições pelas quais a realidade de apresenta, neste caso gera uma redução quanto aos caminhos possíveis para se agir. Porém, a necessidade dada pelas alternativas, não exclui a escolha dos agentes inclusos nesta situação. Há sempre a possibilidade que precisa ser confirmada, mediante a alternativa escolhida, independente de seu conteúdo. O conceito de possível resguarda invariavelmente que sempre há uma escolha a ser feita, ou seja, que a liberdade é uma realidade ${ }^{23}$. Se Deus fez o melhor e pretendeu sempre o melhor para as criaturas, isto pode ser interpretado a partir na noção do que Leibniz pensa como liberdade. Tanto as más quanto as boas escolhas não implicam que são necessárias para Deus, mas são decorrências das ações livres dos homens. Por isso:

\footnotetext{
"Pode ser que tanto para o Sr. Hobbes quanto para o Sr. Espinoza, sabedoria, bondade, justiça não sejam senão ficções com relação a Deus e ao universo; a causa primitiva agindo, segundo eles, pela necessidade de seu poder (puissance), e não pela escolha de sua sabedoria: opinião da qual eu já mostrei suficientemente a falsidade." 24
}

Além de ser um tema clássico e consagrado, a Teodicéia representa uma inflexão fundamental no pensamento de Leibniz. Em grande parte é a ação do princípio de razão suficiente que intenta uma adequação entre os reinos da graça e o reino da natureza, entre corpo e alma, entre o milagre e o mistério. Outro raciocínio que impera na análise de Leibniz é o de harmonia, que busca, senão minimizar pelo menos reconciliar dualismos históricos. Este movimento em sua totalidade apresenta a tentativa de enquadrar a realidade do mundo em uma estrutura racional, não apenas matemática ou lógica, mas que levasse em consideração uma comunidade de mônadas. O melhor dos mundos possíveis, sob alguns aspectos de uma visão ortodoxa cristã, cobraria de Deus a dívida pelo mundo que o homem ainda não teve acesso. No entanto, a filosofia leibniziana coloca este mundo como um caminho aberto para a razão, capaz, sobretudo, de inventar a sua própria realidade mediante as escolhas empreendidas.

\section{LEIBNIZ, UM FILÓSOFO DA POLÍTICA?}

Que Hobbes, assim como Maquiavel, Espinosa, Locke e Rousseau são pensadores consagrados na política, é uma empresa já consolidada em áreas como a filosofia e a ciência política. Suas contribuições são inestimáveis para as várias interpretações, leituras, estabelecimentos e quedas de governos e sistemas de governo a partir de século XV. Por outro lado, a vinculação de Leibniz ao pensamento político se dá por outros caminhos, que não levam diretamente a uma obra sobre o tema, nos moldes da própria Teodicéia ou dos Novos Ensaios sobre o Entendimento Humano. Em noções complexas e completas tais como: 1) o projeto de uma língua universal, que nos Novos Ensaios extrapolam a questão do conhecimento; 2) a idéia de alteridade, que aparece de forma clara na defesa da cultura chinesa, no Discurso sobre a Teologia Natural dos Chineses; 3) a sistematização da subjetividade e da noção de identidade, nos universos densos da Monadologia e Princípios da Natureza e da graça Fundados na Razão; 4) o problema da liberdade, da presença do mal no mundo ou um tratado da natureza humana na Teodicéia.

Todos estes textos, entre outros, representam o pensamento de Leibniz sob 
diversos aspectos dando uma dimensão sobre as possibilidades conceituais de transpor as noções filosóficas deste autor para a esfera da ética e da política. Esta seria a possibilidade de uma análise indireta dos conceitos leibnizianos e como algumas concepções, por exemplo, de natureza e de indivíduo, são herdeiras de uma tradição filosófica e sofrem alterações cujas consequências diretas são a recepção pela tradição de seu sistema de idéias. Por outro lado, Leibniz aparece historicamente engajado nos destinos políticos da Europa, tendo como atividade profissional principal a de conselheiro das mais diversas cortes. Em períodos de grande contato com o poder, Leibniz pôde exprimir algumas de suas idéias sobre os meandros da política, no exercício pleno do cargo que fora incumbido. Basta acompanhar a discussão com o Abade de Saint Pièrre, que data de 1715, cujo tema é o projeto de paz perpétua para a Europa.

Leibniz estuda e comenta o projeto elaborado e difundido pelo clérigo, manifestando que está "convencido de que um projeto tão grande é viável, e que a sua execução seria uma das coisas mais úteis no mundo." ${ }^{25}$ Porém, Leibniz têm consciência plena das dificuldades de execução de uma obra deste porte. Desde as diferenças mercantis, econômicas, de línguas nacionais e dialetos regionais, hábitos e fundamentalmente, as diferenças religiosas. Na esteira desta última questão, Leibniz discute em correspondência com Madame de Brinon ${ }^{26}$, uma proposta de reunificação das igrejas, em especial, católicos e protestantes. Discutindo à partir de seis vias de argumentação - tolerância mútua, disputa ou da discussão, acomodação, aclaração, abstração e condescendência - Leibniz procura um meio pelo qual o diálogo entre estas duas vertentes importantes do cristianismo possam voltar a constituir-se em uma unidade. Para tal promove uma divisão dos pontos de discrepância de acordo com os seus graus de maior ou menor importância.

Propõem então, após descrever os pontos de vista de uma e outra doutrina, duas questões: a primeira é que as decisões dos concílios pudessem ser revistas pelos católicos; a segunda, que a tolerância dos protestantes pudesse se dar para com alguns pontos discordantes dos ritos do catolicismo. Em um único movimento, Leibniz parece justapor os pontos nevrálgicos das duas doutrinas, ao sugerir que alguns dogmas pudessem ser revogados e que se passasse imediatamente da teoria para a prática havendo de fato uma atitude de tolerância. Pois ao se chegar "a um acordo no principal, quer dizer, estando dispostos os povos protestantes a voltar para a Igreja e o Papa a acolher-lhes, a Igreja não terá objeções em fazer concessões em certas questões." ${ }^{27} \mathrm{O}$ problema em questão é só um exemplo deste engajamento, em conjunto com a proposta de Leibniz ao rei da França em invadir o Egito ou ao desejo de organizar uma academia científica na Alemanha, seguindo as experiências da Inglaterra e da França em apoio ao desenvolvimento das ciências e das artes em geral.

Destes posicionamentos já é possível vislumbrar uma idéia de um bem comum ou estabelecimento de instâncias de entendimentos, capaz de se propor a meios para solucionar a mais grave das pendências. Estas são algumas reflexões propostas no bojo da filosofia leibniziana. Sua noção de razão, com a mesma segurança da razão hobbesiana abre espaços importantes para a solução de problemas não só atuais, mas vindouros, que exigem, sobretudo, a liberdade para encontrar o caminho em meio as novidades a serem descobertas sobre a riqueza da natureza humana e suas ações. Nesta perspectiva, ele manifesta que: 
"No fundo, eu acredito que não é preciso reprovar senão os seguidores de Hobbes e de Espinosa porque eles destroem a liberdade e a contingência; pois acreditam que aquilo que acontece é a única possibilidade e deve acontecer por uma necessidade bruta e geométrica. Hobbes tornava tudo material e o submetia tão somente às leis matemáticas; Espinosa também subtraia de Deus a inteligência e a escolha, deixando-lhe um poder cego, do qual tudo emana necessariamente." 28

O cálculo é a forma pela qual a razão se manifesta. Porém, sua capacidade é muito mais ampla e sua abertura é bem maior, sem, no entanto perder em nenhum momento o rigor que lhe é característico. Por isso, é pela via da idéia de possibilidade, que poderíamos iniciar uma reflexão sobre o pensamento político de Leibniz. A política, mais do que o palco privilegiado de atuação das paixões da alma, torna-se também o espaço de administração deste vasto universo de sentimentos, volições e inclinações naturais do espírito. Leibniz procura demonstrar que a grandeza da essência que constitui todos os elementos que compõem o mundo, não podem ser entrelaçadas ou cercadas por nenhuma fórmula que se proponha a restringir os movimentos de fluxo e refluxo destes fenômenos. Mais do que um cálculo necessário, são as probabilidades que confirmam, por vezes, caminhos e possibilidades que adentram no quociente final de resultados, obscuros até então, e claros à partir do instante em que aparecem. A consciência desta grandeza é uma propedêutica à complexidade do universo, e consequentemente, uma compreensão parcial e possível, do que pode o homem.

\section{REFERÊNCIA}

HOBBES, Thomas. Breve Tratado sobre os Primeiros Principios. Scientiae Studiae, São Paulo, v. 4, n. 2, p. 307-33, 2006

HOBBES, Thomas. Elementos de Filosofia- Sobre o Corpo. Computação e Lógica, Parte I. Tradução e Apresentação de José Oscar de A. Marques. Campinas, IFCH:Unicamp (Clássicos da Filosofia. Cadernos de Tradução 12)

HOBBES, Thomas. Leviatã. Os Pensadores. Tradução de João Paulo Monteiro e Maria Beatriz Nizza da Silva. São Paulo: Editora Nova Cultural, 1977.

COUTURAT, Louis. La logique de Leibniz : d'après des documents inédits. Ancienne Librairie Germer Baillière, 1901, Paris.

LEIBNIZ, G.W. Reflexões sobre a obra que o Sr. Hobbes publicou em inglês, sobre a liberdade, a necessidade e o acaso. Tradução e notas: William de Siqueira Piauí e Juliana Cecci Silva. Revista Transformação. São Paulo, 30(2): 261-272, 2007

LEIBNIZ, G.W. Escritos Filosoficos. Tradução de Roberto Torretti, Tomás E. Zwanck e Ezequiel de Olaso. Buenos Aires: Editorial Charcas, 1982. p. 666.

LEIBNIZ, G.W. Escritos Políticos. Seleccion, Traduccion, Notas de Jaime de Salas. Centro de Estudos Constitucionales, Madrid, 1979.

LEIBNIZ, G.W. Discurso sobre la Teología Natural de los Chinos. Traducción de Lourdes Rensoli Laliga. Biblioteca Internacional Martin Heidegger, Edicción Bilingue, Buenos Aires, 2000.

LEIBNIZ, G.W. Essais de Théodicée. Flamarion, 2008, Paris.

LEIBNIZ, G.W. Ensaios de Teodicéia- sobre a bondade de Deus, a liberdade do homem e a origem do mal. Tradução, introdução e notas: Juliana Cecci Silva e William de Siqueira Piauí, Editora Estação Liberdade, São Paulo, 2013.

LEIBNIZ, G.W. Die philosophischen Schriften. Ed. C I. Gerhardt, 7 vols., Berlim, Halle: 194963.

LEIBNIZ, G.W. Oeuvres de Leibniz. Ed. by L. A. Foucher de Careil, 6 vols., 1st edn., Paris, 1859-65 ; vol. 7, 2nd edn., Paris, 1875.

MALHERBE, Michel. Liberdade e necessidade na filosofia de Hobbes. Cad. Hist. Fil. Ci., 
Campinas, Série 3, v. 12, n. 1-2, p. 45-64, jan.-dez. 2002.

SKINNER, Quentin. Razão e Retórica na Filosofia de Hobbes. Tradução de Vera Ribeiro, Ed. Unesp, São Paulo, 1999.

SKINNER, Quentin. Hobbes e a liberdade republicana. Tradução de Modesto Florenzano. São Paulo: Edunesp, 2010.

RIBEIRO, Renato Janine. Ao leitor sem medo - Hobbes escrevendo contra seu tempo. Editora UFMG, $2^{\text {a }}$ Edição, São Paulo, 1999.

VILANOVA, M.G; BARROS, D.F. (Org.) Hobbes: Natureza, História e Política. São Paulo, Discurso Editorial, 2009.

\section{Notas}

1 Obra disponível na BNF, intitulada em seu original como Système Religieux de Leibnitz, tendo a sua primeira publicação em 1819 .

2 Ao comentar sobre as várias leituras sobre Hobbes, de Borges a Gueroult, Renato Janine Ribeiro escreve que: "(...)as imagens mais correntes acerca de Hobbes, resultam na eleição de alguns temas chave: $\mathrm{O}$ medo, a guerra de todos, o Estado Todo-poderoso; - à custa do obscurecimento de outros. A esperança, o poder da lei: humoristas, teólogos, panfletários fazem, de Hobbes, uma charge. Será reação irritada sobre o homem e as teses sobre a política- ou será também, um sinal de forca ou sedução das imagens que ele propõe" Pag. 19.

3 Leibniz, 2007, p. 263.

4Elementos da Lei Natural e Política, 2002, p. 20.

5 “(...) rapidez na passagem de um pensamento a outro.” Hobbes, 1979, p.43.

6 Idem, ibidem.

7 Hobbes, 2006, p. 311.

8 Leibniz, 2007, p. 263.

9 Esta distinção está no capítulo XI, de título 'Das diferenças de costumes'.

10 Hobbes, 1979, p. 60.

11 Idem, Ibidem

12 Idem, Ibidem

13 Idem, Ibidem

14 Hobbes, 1998, p. 29

15 Hobbes, 2009, p.17.

16 Ribeiro, Renato Janine. Introdução ao 'De Cive', em que o professor insiste na tese realista de Hobbes, justamente por ter em vista uma dupla preocupação: a determinação dos corpos (seu movimento de fluxo e refluxo) e o contexto europeu, no que se refere a movimentação dos ingleses e as sucessões do trono, bem como as alianças feitas.

17 Hobbes, 2009, p.21.

18 “(...)isso é deduzido da própria definição de filosofia, cuja tarefa é a de investigar uma propriedade a partir da geração ou a geração a partir de uma propriedade; donde se compreende, portanto, que, ali onde não há nenhuma geração ou propriedade, não há filosofia. Portanto, a filosofia exclui de si a Teologia, ou seja, a doutrina da natureza e dos atributos de Deus, eterno, inegável, incompreensível, e acerca do qual não se pode estabelecer nenhuma composição ou divisão, nem conceber alguma geração. (...) Exclui a história, tanto natural quanto política, ainda que seja muito útil ( e mesmo necessária) para a filosofia, porque tal conhecimento é ou experiência ou autoridade, e não raciocínio." Hobbes, 2009, p.33

19 Hobbes, 2009,p. 31.

20 Idem, p. 40.

21 Leibniz, 2007, p. 265.

22 Leibniz, Teodicéia, § 288.

23 "O concurso físico de Deus e das criaturas com a vontade também contribui para as dificuldades com relação à liberdade. Eu sou da opinião que nossa vontade não apenas é 
isenta de coação, mas, além disso, da necessidade. (...) Quando agimos livremente, não somos forçados, como aconteceria se fôssemos empurrados em direção a um precipício e fôssemos jogados do alto para baixo; não somos impedidos de ter o espírito livre quando deliberamos, como aconteceria se fosse nos dado uma bebida alcoólica que nos tirasse a capacidade de julgar. Existe contingência nas incontáveis ações da natureza; mas quando 88 o julgamento não está naquele que age, não existe liberdade.” Leibniz, Teodicéia, § 245. 24 Leibniz, 2007, p. 267.

25 Correspondência com Abade de Saint-Piérre, in Die philosophischen Schriften. Ed. C I. Gerhardt, 7 vols., Berlim, Halle: 1949-63.

26 Correspondência de 1694-1695, in Oeuvres de Leibniz, ed. by L. A. Foucher de Careil, 6 vols., 1st edn., Paris, 1859-65 ; vol. 7, 2nd edn., Paris, 1875.

27 Leibniz, 1979, p. 236.

28 Leibniz, Teodicéia, § 299 